\title{
PERFORMANCE ANALYSIS AND EXHAUST EVALUATION OF CI ENGINE USING WASTE COOKING OIL AND DIESEL BLEND
}

\author{
Mr. Saiphan L Jamadar \\ Mechanical Department, \\ Nagesh karajgi ORCHID College, \\ Engg \& Tech, Solapur, Maharashtra
}

\author{
Prof. Suryaji.S. Kale \\ Mechanical Department, \\ Nagesh karajgi ORCHID College, \\ Engg \& Tech, Solapur, Maharashtra
}

\begin{abstract}
The improved consideration concerning fundamental of vitality supplies, fuel sources and the biological effect, natural effect and request of fuel and so on., this all components is expanded to enthusiasm towards the new examination of progressive wellsprings of vitality for non-renewable energy sources. Because of the environmental difficulty brought about by the utilization of petroleum derivatives, consideration has been paid to the creation of biodiesel as a choice to fuel. Vitality utilization is rising while petroleum products, the primary wellspring of vitality, compromise their decrease and relating their fairly estimated worth increments. To satisfy this necessity Biodiesels will have a significant impact as option in contrast to diesel oil/fuel since they are sustainable and have comparative properties. This paper objective is to give an away from and see on age of Biodiesel from utilized waste cooking oil and to likewise examination distinctive strategy and result. Biodiesel is a naturally, biologically cordial elective diesel fuel produced using vegetable oils, squander cooking oil and creature fats and so on.

The current strategy for biodiesel creation is the transesterification of the unpalatable oil with a liquor (methanol or ethanol) within the sight of an impetus or not.

This paper planned to give outline of biodiesel creation from WCO and to contemplate the diverse response; different techniques and impetuses utilized and locate the better state of its procedure. Additionally different factors are checked incorporate response, properties, for example, temperature, thickness, proportion of liquor to vegetable oil, impetus, and power of blending, virtue of reagents etc. This study expects to make a relative investigation of transesterification forms by various technique use for biodiesel creation. The consequences of this examination recommend that the creation of biodiesel can be done and its got were discovered practically identical to unadulterated biodiesel.
\end{abstract}

Keyword: Transesterification process, making biodiesel, WCO, FFA.

\section{INTRODUCTION}

Due to of environmental change and air contamination brought about by the burning emanations of non-renewable energy sources. Increment in deficiency of oil assets all over world the ecological issues brought about by the utilization of petroleum derivatives, so consideration has been paid to look for some elective energizes the creation of biodiesel as an option in contrast to diesel.

Biodiesel can be making from any material that contains unsaturated fats, additionally different vegetable fats and oils, creature fats, squander oils, and palatable oil handling squanders can be utilized as feed stocks for biodiesel creation.

Presently at present strategy for use for making biodiesel creation is the transesterification procedure of the creature fats, consumable oil etc. With a liquor (methanol or ethanol) within the sight of an impetus or not.

Biodiesel has gotten one of the great substitutions to the issues of economical turn of events, non-particulate issue contaminations, harmfulness and biodegradability, vitality security, and the critical decrease of ozone depleting substances emanations.

Biofuel has remarkable properties fundamentally the same as those of fossil diesel, yet with emanations of sulfur, carbon dioxide (CO2) and a lot littler particles. Biodiesel is presently suggested as an elective fuel since it has a few favorable circumstances over ordinary diesel. It is protected, sustainable and non-poisonous. The decrease of fossils powers is clear claim from mainstream researchers alongside condition concerns. In this way it is exceptionally basic to need the substitute wellspring of vitality which is condition benevolent, having more noteworthy or equivalent productivity than the petroleum derivative. Elective new and inexhaustible fuel can offer solution for social issues concern fuel. Among these sustainable power sources biodiesel is probably the best source to utilize it in diesel motors with no alteration. 


\section{International Journal of Engineering Applied Sciences and Technology, 2020 \\ Vol. 5, Issue 2, ISSN No. 2455-2143, Pages 639-644 \\ Published Online June 2020 in IJEAST (http://www.ijeast.com)}

A. Biodiesel can be prepared from many methods. Some of They are listed below

1) Thermal cracking

2) Micro emulsions

3) Direct using or blending

4) Transesterification

This examination intends to make a near report transesterification forms for biodiesel creation. This point of paper centers around the Trans esterification process. The Trans esterification is the most widely recognized procedure used underway of biodiesel. This Biofuel is characterized as unsaturated fat methyl ester (Acclaim) got from triglycerides (vegetable oil/creature fats) and liquor by utilizing distinctive with right proportion of impetus.

Biodiesel creation is the procedure of where delivering the biofuel, through the concoction responses of transesterification and esterification. For this require vegetable or creature fats and oils being responded with short-chain of alcohols and included with impetus (regularly methanol or ethanol).

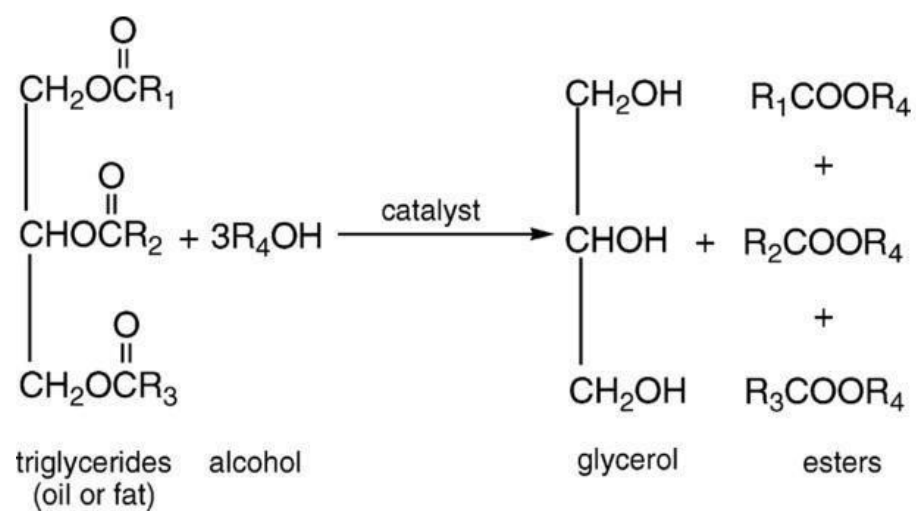

Fig 1.Transesterification reaction

The liquor responds with the unsaturated fats to frame the mono-alkyl ester, or biodiesel, and rough glycerol. As appeared in Fig 1.

So here contemplated following distinctive philosophy of making biodiesel.

\section{METHODOLOGY}

1.In This transesterification procedure we have utilized seventh biodiesel tests (A,B,C,D,E,F,G)and after the procedure of methanol vanishing the resultant biodiesels were left to lie for in any event 8 hours. So detachments were utilized to isolate the top (methyl ester) and base (glycerol) layers of the biodiesel structure given examples. The top layer was essentially made out of free unsaturated fat methyl esters. The base side store was for the most part comprised of glycerol, salts, cleanser, different polluting influences and overabundance methanol as it is a polar compound for
In this procedure sunflower, palm, olive, canola, soybean, rapeseen, cotton seed and peanuts oils, and creature based lipid (for example spread). Squander creature fat or oils are responded with Methanol, utilizing a solid soluble impetus (sodium hydroxide $\mathrm{NaOH}$ or potassium hydroxide $\mathrm{KOH}$ ). During this transesterification forms, the triglyceride is responded with liquor within the sight of an impetus, generally a solid Soluble like sodium hydroxide.

\begin{tabular}{|c|c|c|c|c|c|c|c|}
\hline $\begin{array}{c}\text { Sr. } \\
\text { no }\end{array}$ & $\begin{array}{c}\text { Sam } \\
\text { ples }\end{array}$ & $\begin{array}{c}\text { UC } \\
\mathbf{O} \\
(\mathbf{m l}\end{array}$ & $\begin{array}{c}\text { Met } \\
\text { han } \\
\mathbf{o l}\end{array}$ & $\begin{array}{c}\text { KOH } \\
\text { gram } \\
\mathbf{~ s}\end{array}$ & $\begin{array}{c}\text { Temp } \\
\text { eratu } \\
\text { re } \\
\left({ }^{\circ} \mathbf{C}\right)\end{array}$ & $\begin{array}{c}\text { Glyce } \\
\text { rol }\end{array}$ & $\begin{array}{c}\text { Bio } \\
\text { diesel } \\
(\mathbf{m l})\end{array}$ \\
\hline 1. & $\mathrm{A}$ & 100 & 20 & 0.98 & 70 & 26.46 & 80 \\
\hline 2. & $\mathrm{~B}$ & 100 & 15 & 1.6 & 70 & - & - \\
\hline 3. & $\mathrm{C}$ & 100 & 15 & 1.146 & 70 & 26.6 & 83.40 \\
\hline 4. & $\mathrm{D}$ & 100 & 17 & 1.207 & 70 & 29.20 & 82.8 \\
\hline 5. & $\mathrm{E}$ & 100 & 10 & 1.109 & 70 & - & - \\
\hline 6. & $\mathrm{~F}$ & 100 & 12 & 1.153 & 70 & 27.64 & 79.35 \\
\hline 7. & $\mathrm{G}$ & 100 & 15 & 1.250 & 70 & 26.04 & 83.12 \\
\hline
\end{tabular}

example it parcels more with polar glycerol rather than the non-polar methyl esters.

The samples (A,B,C,D,E,F,G,H) are set up on various pieces of triglycerides and liquor .as appeared on table 1 .

Table 1Samples compositions

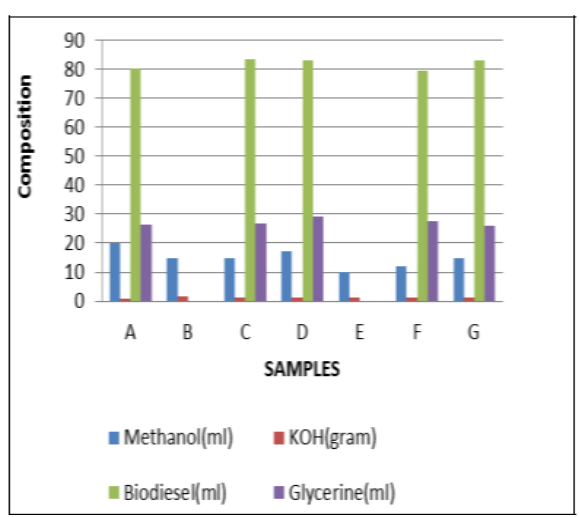

Here for the situation test B and E brings about lathery arrangement as appeared in fig 2. This test shows that a lot of impetus

Results in increment in alcholysis and not creation of biodiesel. The examples $\mathrm{C}$ and $\mathrm{D}$ are taken into examination to investigations the properties and execution in motor. The examples C and D are considered and B20 (20\% Biodiesel+80\% Oil diesel) is readied.

\section{METHODOLOGY 2}




\section{International Journal of Engineering Applied Sciences and Technology, 2020 \\ Vol. 5, Issue 2, ISSN No. 2455-2143, Pages 639-644 \\ Published Online June 2020 in IJEAST (http://www.ijeast.com)}

The biodiesel is prepared from waste cooking oil sample collected from a local area. Here the biodiesel was characterized for its physical and fuel properties using ASTM standard methods for biodiesel fuel quality assurance. The arrangement of final biodiesel was defined by physical properties such as density, viscosity, flash point, water content and acid value.

\begin{tabular}{|c|c|c|c|}
\hline Sr.no & Property & Value & unit \\
\hline 1 & Density & 87 & $\mathrm{~g} / \mathrm{cm} 3$ \\
\hline 2 & $\begin{array}{l}\text { Kinematic } \\
\text { viscosity }\end{array}$ & $35.4-40$ & $\mathrm{~mm} 2 / \mathrm{s}$ \\
\hline 3 & $\begin{array}{l}\text { Flash } \\
\text { point }\end{array}$ & 130 & ${ }^{\circ} \mathrm{C}$ min. \\
\hline 4 & $\begin{array}{l}\text { Asid } \\
\text { number }\end{array}$ & 0.80 & $\begin{array}{l}\mathrm{mg} \\
\mathrm{KOH} / \mathrm{g} .\end{array}$ \\
\hline 5 & $\begin{array}{l}\text { Water } \\
\text { content }\end{array}$ & $\begin{array}{l}\text { Max } \\
0.005 \% .\end{array}$ & --- \\
\hline
\end{tabular}

Table .2 Main properties of WCO

\section{RESULT:}

Fig. 3 show two layer division among glycerol and Acclaim (unsaturated fat methyl esters), At the top will be nearness Distinction and the at base is glycerol.

To diminish the high thickness of triglyceride (TG). Methanol and impetus produce methyl ester and glycerol.

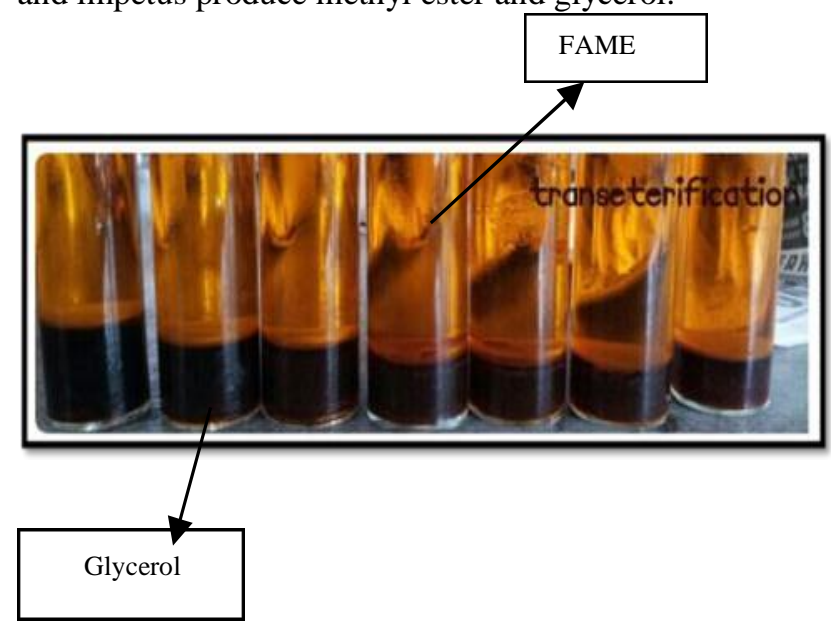

Fig. 3Transesterification process result

\section{METHODOLOGY 3}

In this examination, assembling of biodiesel was acted in a little cluster reactor by transesterification of waste cooking oil with including potassium hydroxide impetus. The washing of biodiesel is actualized by two strategies for example washing with refined water and washing with vinegar. Valuation of waste cooking oil for finding the free unsaturated fat substance and their lessening with the glycerolysis in nearness of Zncl as an impetus to improve the transesterification was contemplated.
Effect of waste cooking oil on transesterification reaction The bend indicated that with $\mathrm{Zncl}$ as impetus the FFA get decreased in sum in low time and that without Zncl impetus it required more opportunity to lessen the FFA substance. Here consider the impact of FFA percent and the water content in the production of biodiesel the water must not surpass $0.3 \%$ and with the FFA percent under 3\%w/w.

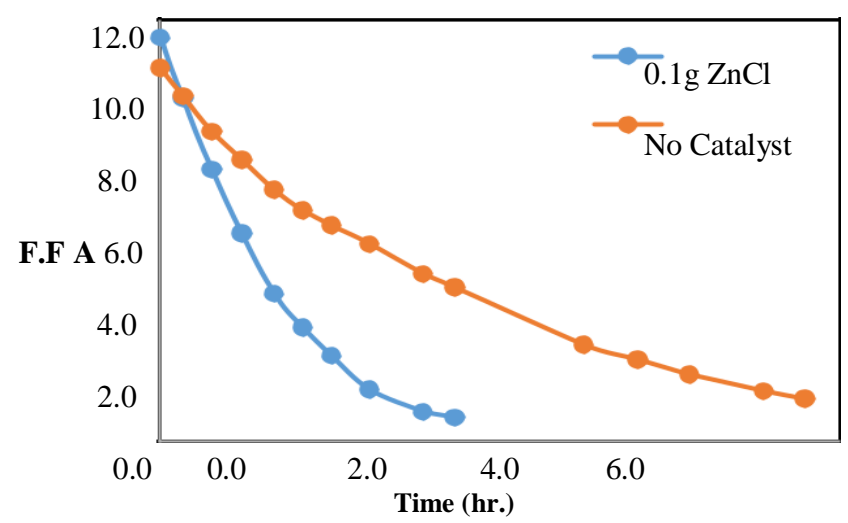

Fig. 4 Reduction of Fatty Acids by Glycerolysis.

\section{Effect of the catalyst loading}

This is examined that impetus stacking impacts the progressions of the triglycerides into monoglycerides.

The bend shows high return of about $88 \%$ at $7 \mathrm{~g}$ impetus. It is finding that more increment in sum from $7 \mathrm{~g}$ have no impact on the transformation of triglyceride.

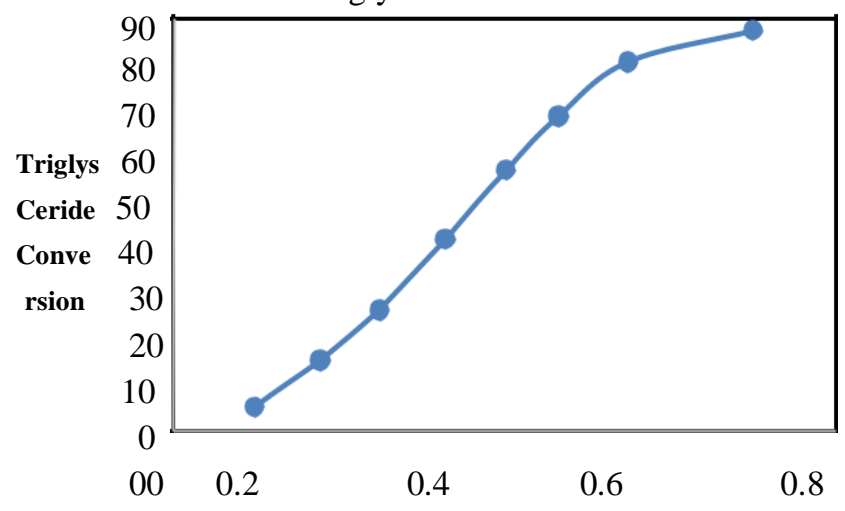

Fig. 5 Effect of the catalyst loading on the conversion of the Triglycerides.

In this study conversion to ester was about $69 \%$ w/w with molar ratio of $6: 1$. High yield of $(84 \%)$ ethyl ester was observed at 12:1 molar ratio.

\section{METHODOLOGY 4}

Density and compressibility are fundamental standard for the expansion of diesel motor activity. With this goal, these properties were accounted for squander cooking oil biodiesel and its mixes blended in with diesel. Here in this idea thickness estimations were done overen enormous scopes of 
weight $(0.1$ to $140 \mathrm{MPa})$ and temperature (293.15 to $353.15 \mathrm{~K})$ perfect with motor applications.

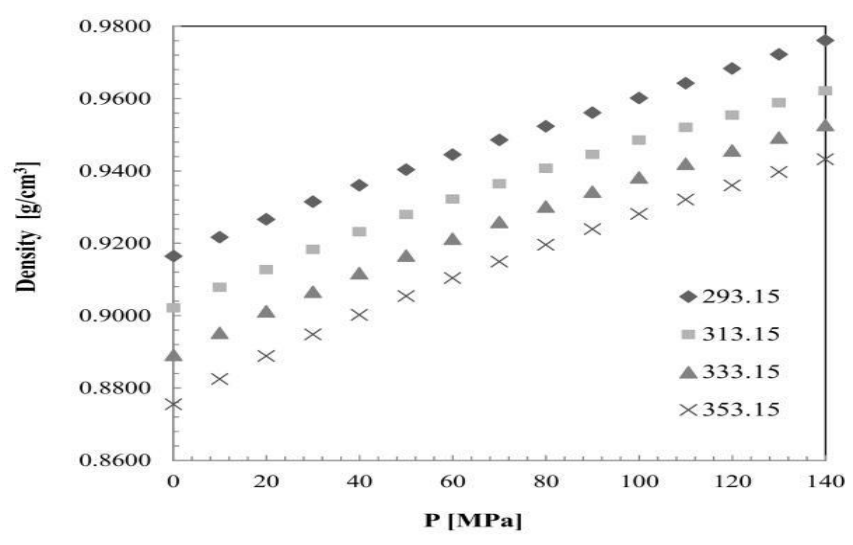

Fig. 7 Variation of the WCO biodiesel density as a function of pressure at different temperatures.

Density estimations were done along different isotherms divided at $20 \mathrm{~K}$ spans (from 293.15 to $353.15 \mathrm{~K}$ ) and for pressures (extending from 0.1 to $140 \mathrm{MPa}$ ) in steps of $10 \mathrm{MPa}$.

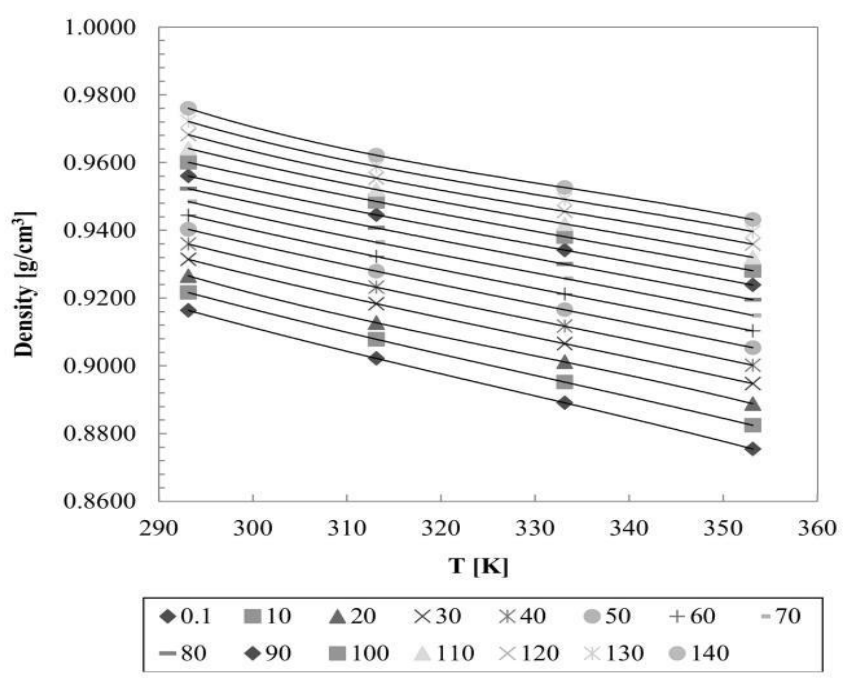

Figure 8 Variation of the fresh biodiesel density as a function of temperature at different pressures ( 0.1 to $140 \mathrm{MPa})$.

\section{METHODOLOGY 5}

This exploration goal to contemplate the dynamic response of waste cooking oil by transesterification into biodiesel and locate the best condition of its procedure. The examination was finished by transesterification response in cluster reactor. These outcomes were utilized to compute the yield of change and ester substance of biodiesel test.

The effect of temperature:
This exploration is done in squander cooing oil to methanol (liquor) volume proportion 170:80, here use impetus focus 1 wt. $\% \mathrm{KOH}$, and time required hour long. The temperature variety s keep up in 50,60 , and $66.5 \mathrm{oC}$ so as the greatest temperature that can be coming to in the response process.as demonstrated fig.9.

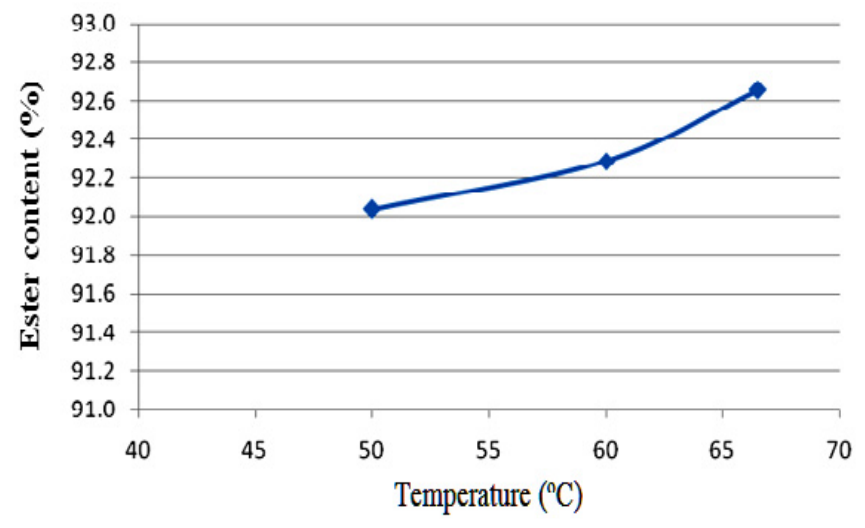

Fig. 9. The effect of temperature to the ester content of product

This diagram show graphical of connection among temperature and the ester content in Fig.9 and we can see that if temperature increments so it little increments in the ester substance of item.

The effect of catalyst concentration:

These examination shows of realistic connection between impetus fixation and the ester substance can be seen in fig. 10 . What's more, utilized impetus focuses $1,2,3$, and $4 \%$.

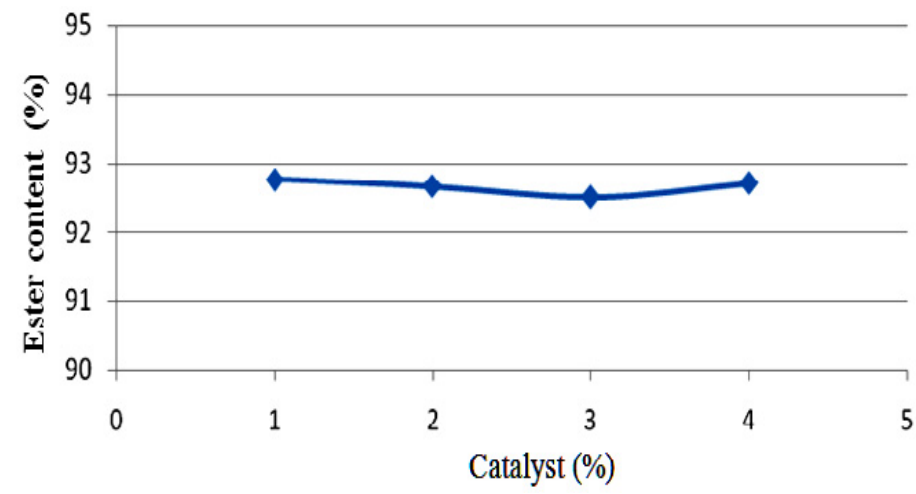

Fig. 10. The effect of catalyst concentration to the ester content.

This exploration was done at temperature 650C; of waste cooking oil to methanol volume proportion 200:50 (molar proportion 1:6.18) and response time hour long. So we can see that the realistic plot is practically steady with a little decline. They said that there was no impact in molar proportion and impetus focus distinction to the yield of biodiesel creation. 


\section{International Journal of Engineering Applied Sciences and Technology, 2020 Vol. 5, Issue 2, ISSN No. 2455-2143, Pages 639-644 \\ Published Online June 2020 in IJEAST (http://www.ijeast.com)}

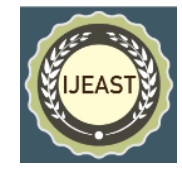

\section{CONCLUSION}

Biodiesel is a decent substitute fuel for diesel motors since it is biologically agreeable and inexhaustible. From this above exploration it is cleared that Bio diesel is subsequently an astounding inexhaustible fuel source. There is various techniques use for delivering biodiesel, however the vegetable oil, squander cooking oil transesterification and fats is the strategy for the most part utilized these days. The handling innovation for creating bio diesel is very much evolved and presents minimal Mechanical hazard.

All the scientists are concentrating more on creating biodiesel utilizing consumable oils or waste cooking oil, yet their utilization for biodiesel creation has caused incredibly to decreasing its expenses. It is a viable option with the possibility to altogether improve nature. Biodiesel is an excellent diesel elective fuel and is most likely the best answer for ozone harming substance and contamination issues. The above synthesis of last biodiesel was controlled by physical properties, for example, thickness, consistency, streak point, water substance and corrosive worth, it has presumed that the estimations of all properties were like that of standard particulars for biodiesel.

Moreover, the centralization of impetus and liquor utilized in transesterification process are change which can impact on biodiesel creation.

The ideal condition (the ester content $92.76 \%$ ) of biodiesel creation were gotten at temperature $66.5 \mathrm{oC}$, molar proportion of methanol to oil $6.18: 1$, and 1 wt.\% of impetus fixation and biodiesel item from second-utilized cooking oil is proper with standard.

The significant favorable position of Biodiesel contrasted with different options, for example, flammable gas or power, is that it tends to be utilized without alteration in different fuel-based applications particularly in existing diesel Engine.

\section{REFERENCE}

[1] Gopalakrishnan S,J.Ubaidullah P.Shanmugasundaram K, YuvarajT,Tamilarasu (2017):Production of Biodiesel From used Cooking Oil (IJIRST/Conf/RAME/2017/015)

[2] Nor Hazwani Abdullah, Sulaiman Haji Hasan, Nurrul Rahmah MohdYusoff(2013):Biodiesel Production Based on Waste Cooking Oil (WCO) (ijmse.1.2.94-99 Vol.1, No.2December 2013).

[3] Nor Alam,Muzzamail Hussain, Faisal Mushtaqa, Muhammad Shahid (2016):Production of Biodiesel from waste Cooking oil by Transesterification process using Potassium Hydroxide as Catalyst(IJCEE Dec 2016 Volume7,No.4) .

[4] ThanhXuan NguyenThiID, Jean-Patrick Bazile and David Bessières(2018):Density Measurements of waste Oil Biodiesel and Diesel Blends Over Extended
Pressureand Temperature Ranges (Energies 2018, 11 Doi:1212; 10.3390/en11051212.) .

[5] Wanodya Asri Kawentara and Arief Budimanb (2012):Synthesis of biodiesel from second-used cooking Oil EnergyProcedia 32 (2013) 190 - 199).

[6] Sunthitikawinsakul A and Sangatith N(2011): Study on the Quantitative Fatty Acids Correlation of Fried Vegitable Oil for Biodiesel with Heating Value (Procedia Engineering 32 (2012) 219 - 224).

[7] MontchoPapin S., Konfo T. R. Christian, Agbangnan D. C.Dominique(2018):Comparative Study of

Transesterification Processes for Biodiesel Production -A Review (Elixir Appl. Chem. 120 (2018) 51235-51242 51235.)

[8] Alemayehu Gashaw, AbileTeshita (2014):Production of biodiesel from waste cooking oil and factors affecting its formation: A review (ijrsedoi: 10.11648/ j.ijrse. 20140305.12).

[9] An,HYangW.M,MaghbouliA,Chou,J.Li,S.K,Chua,K.J.(20 13):Performance combustion and emission Characterestics of biodiesel derived from waste cooking oilEnergy, 112(2013),pp.493-499,0.1016/j.apenergy .2012.12.044.

[10] Kalam M A,MasjukiH.H,JayedM.H,Liaquat A.M.E36(2011): Emission performance characteristics of an indirect ignition diesel engine fuelled with waste cooking oil,(pp.397-402, 10.1016/j.energy.2010.10.026.).

[11] Xue J,Klemes J.J.(2013):Combustion characteristics, engine performances and emissions of waste edible oil biodisel in diesel Engine( Energy Rev, 23 (2013), pp. 350-365, 10.1016/j.rser.2013.02.039).

[12] OzsezenA N, CanakciM.52 (2011):Determination of performance and combustion characteristics of a diesel engine fueled with canola and waste palm oil methyl ester( pp. 108-116,10.1016).

[13] B. Freedman, E.H. Pryde, T.H. (1984):Variables Affecting the Yields of Fatty Esters from Transesterified Vegitable Oil, JACOS 61 (1984) 1638-1643 Peoria, I L 61604,.

[14] K. Muralidharan, D. Vasudevan. Energy, 88 (2011) :Performance,emission and combustion characteristics, of a veriable compression ratio engine using methyl esters of waste cooking oil and diesel blends (pp.3959396810.1016/j.apenergy.2011.04.0.14).

[15] Barnwal B.K. and Sharma M.P.(2005):Prospects of biodiesel production from vegetable oils in india(Energy Review, vol. 9, no. 4, pp. 363-378, 2005).

[16] Kulkarni MG, Dalai A K(2006):Waste Cooking Oil - An Economical Source for Biodiesel: A review (IndEngChem Res 45 (2006), 2901-13). 
[17] Shi X, Yu Y, He H, Shuai S, Wang J, Li R , Fuel 84 (2005):Emission Characteristics using methyl fuel blends soyate ethanol-diesel on a diesel engine, ( doi:10.1016/j. fuel.2005.03.001).

[18] MustafaÇANAKÇI, A. NecatiÖzsezen(2005): Evaluating Waste Cooking Oils As Alternative Diesel fuel G U. J. Sci., 18(1):81-91 (2005).

[19] NabanitaBanerjeea, RiticaRamakrishnana,

TusharJasha(2013): Biodiesel Production From Used vegitable oil collected From Shops Selling Fritters In Kolkata,(doi: 0.1016/j.egypro.2014.07.259ICAER/2013).

[20] Balat Mustafa, BalatHavva(2009):Recent trends in global production and utilization of bio-ethanol fuel (doi: Mustafa, BalatHavva(2009):Recent trends in global production and utilization of bio-ethanol. 